v.23, n.1, Especial do IV Simpósio de Nutrição de Animais de Companhia, p.05-06, 2018

\title{
INFLUÊNCIA DOS TUTORES NO HÁBITO INGESTIVO DE CÃES
}

(Influence of tutors on the ingestive habit of dogs)

Fernanda de L. Gouvêa', Isadora C. Coelho ${ }^{1}$, Brenda Prato ${ }^{1}$, Geruza S. Machado ${ }^{1}$

\begin{abstract}
${ }^{1}$ Universidade Federal do Rio Grande do Sul
\end{abstract}
Email: fegouvea-zootecnia@hotmail.com

Resumo: O objetivo deste estudo foi avaliar através de um questionário se os tutores podem influenciar o hábito ingestivo de seus cães e ao favorecimento do consumo de outros alimentos além do alimento completo e balanceado. $O$ questionário continha 28 perguntas do tipo misto, com perguntas abertas e fechadas, foi difundido através das redes sociais no período de janeiro de 2018 a abril de 2018, e obteve-se 397 respostas. Através dos resultados foi possível concluir que a rotina dos tutores influencia o hábito ingestivo dos cães, e que os tutores dividem o alimento humano com os cães e influenciam na forma de alimentação desses animais.

Palavras-chave: alimento; consumo; forma de alimentação

Abstract: The objective of this study was to evaluate through a questionnaire whether tutors can influence the ingestive habit of their dogs and favor the consumption of other foods in addition to complete and balanced food. The questionnaire contained 28 mixed-type questions with open and closed questions, was disseminated through social networks from January 2018 to April 2018, and 397 responses were obtained. Through the results, it was possible to conclude that the tutors' routine influences the ingestive habits of the dogs, and that the tutors divide the human food with the dogs and influence in the feeding way of these animals.

Keywords: Food; consumption; feed way

Introdução: O Brasil é o país que apresenta o quarto maior número de animais de companhia (ABINPET, 2014). A convivência frequente dos humanos com cães e gatos, colaborou com o surgimento de novos estudos sobre o comportamento canino e também com a maior preocupação com a saúde, bem-estar e nutrição desses animais (Carciofi et al., 2010), devido aos diversos distúrbios nutricionais que podem surgir. Diante disso, o objetivo deste trabalho foi verificar como os tutores podem influenciar o hábito ingestivo dos cães e fornecimento de alimentos extras que não são diretamente destinados a esta categoria animal.

Material e Métodos: $O$ estudo foi realizado a partir de questionários online com 28 perguntas difundidos através de redes sociais. O questionário era do tipo misto, com perguntas abertas e fechadas, sendo que após as perguntas os tutores poderiam encaminhar uma foto do cão e/ou acrescentar um comentário. O acesso ao questionário foi limitado apenas aos tutores de cães, mas sem delimitações geográficas. Para conhecer o perfil do tutor foram feitas perguntas de caráter socioeconômico. Os entrevistados deveriam responder perguntas sobre o manejo da alimentação dos animais e o hábito ingestivo dos mesmos. Os dados coletados foram analisados com a utilização do programa Microsoft Office Excel através da frequência das respostas. 
Resultados e Discussão: Foram entrevistados 397 tutores, 84\% mulheres, com idade entre $20-30$ anos (53\%), provavelmente devido a difusão via redes sociais, $54 \%$ possuía nível superior de escolaridade (nível superior completo e pósgraduação), $32 \%$ reside com mais uma pessoa, nessas situações a conduta destinada para a alimentação pode ser influenciada se for comparada com residência em que apenas um tutor faz manejo. Costa et al. (2013) verificaram que $72 \%$ dos tutores consideram o animal de estimação como membro da família. Essa relação entre o homem-cão pode afetar o comportamento do animal por influência do tutor ao alimentar o cão, por exemplo, dividindo sua comida com o animal.

A maioria dos tutores fornecem dieta seca como principal componente da alimentação dos cães (69\%), dividida em 1-2 vezes ao dia (60\%) provavelmente pela praticidade ao fornecer essa dieta. Entretanto, mais da metade dos tutores relatam dividir a própria comida com o cão $(51 \%)$, relatam fornecerem o próprio alimento e outros alimentos adicionais. Foram observados que $75 \%$ fornecem frutas, $37 \%$ verduras, $17 \%$ iogurtes, $9 \%$ salgadinhos, $4 \%$ doces (como balas e chocolates) e $8 \%$ todos os citados. Foi verificado que os tutores não consideram esses alimentos como componentes da dieta e não levam em consideração as calorias ingeridas, além de que $54 \%$ dos entrevistados oferecem petiscos destinados a categoria de uma à três vezes ao dia para os cães. Ações que afetam diretamente o consumo calórico destes animais. Podendo favorecer a obesidade e casos de Diabetes.

Apesar disso, mais de $87 \%$ dos tutores não consideram seu cão obeso. No questionário foi solicitado uma foto do cão para verificarmos esta condição, infelizmente poucos tutores enviaram, e não foi possível relacionar a percepção dos tutores sobre a condição corporal verdadeira dos animais. Em estudo com cães obesos Singh (2002), relatou que tutores não reconhecem seu cão com sobrepeso e o ECC médio determinado por especialistas foi de 6,3, enquanto que 0 ECC médio determinado pelos tutores dos cães foi de 5,3. É importante que se faça a orientação correta aos tutores sobre a condição corporal dos cães, para que eles façam a administração de dietas nutricionalmente balanceadas, pois os animais de companhia são totalmente dependentes dos tutores para alimentação e os tutores podem ter uma difícil percepção sobre a obesidade clínica e os seus prejuízos.

Conclusão: Grande parte da alimentação dos cães é influenciada diretamente pelo comportamento e estilo de vida de seus tutores. Isso nos remete a pensar que 0 hábito ingestivo dos cães é influenciado, desde a rotina dos tutores, o tempo que eles despendem aos seus cães, até os hábitos alimentares, como divisão de comida e petiscos e o número de pessoas que residem na casa.

Referências: ABINPET. Perfil Pet Food. Associação Brasileira de Indústrias de Produtos para Animais de Estimação, 2014

CARCIOFI A.C.; JEREMIAS J.T. Progresso Científico sobre a nutrição de animais de companhia, 2010.

COSTA, E.F et al. Influência do proprietário no comportamento de cães. In: XIII Jornada de ensino, pesquisa e extensão, 2013, Recife.

SINGH R, LAFLAMME DP, SIDEBOTTOM-NIELSEN M. Owner perceptions of canine body condition score. J Vet Intern Med;16:362, 2002. 